\title{
Detection of deception through saccadic movements in the psychological assessment and symptom monitoring of Covid-19
}

DOI: $10.46932 / \mathrm{sfjdv2n2-087}$

Received in: March 1st, 2021

Accepted in: May 30th, 2021

\section{Luz Patricia Rodas Ochoa}

Magister in Safety, Health and Environment.

Institution: Laboratory of Psychometry, Ethology and Comparative Psychology. Catholic University of Cuenca

Personal address: Ecuador, Azuay, Cuenca, Alberto Guerrero Martinez between Antonio Pons and Luis Larrea de Alba.

E-mail: luzpatty78@gmail.com; luzpa78@outlook.com

Pablo Andrés Buestán Andrade

Master's Degree in Electronic Systems Engineering. Institution: Postgraduate Unit of the Catholic University of Cuenca

Personal address: Ecuador, Cañar, Azogues, Demetrio Aguilera.

E-mail: pablo.buestan@ucacue.edu.ec

\author{
Andrés Ramírez Coronel \\ Magister Educational Neuropsychology \\ Institution: Catholic University of Cuenca
}

Personal address: Ecuador, Azuay, Cuenca, Humboldt and the Americas.

E-mail: andres.ramírez@ucacue.edu.ec

Pedro Carlos Martínez Suarez

$\mathrm{PhD}$ in Psychology.

Institution: Laboratory of Psychometry, Ethology and Comparative Psychology. Catholic University of Cuenca, CIITT Campus.

Personal address: Ecuador, Azuay, Cuenca, Ricaurte parish, Vía Ricaurte Bibín in front of Plasticos Rival.

E-mail: pmartinezs@ucacue.edu.ec

\begin{abstract}
From the theory of the model of the mind's point of view, which indicates that in syllogisms there will be more eye movements from front to back between the terms of the premises that question some of Ford's predictions? (Espino \& Santamaría, 1998) During the blinking process, sometimes the superior and inferior eyelids tend to completely or incompletely close. It intervenes notably in the comfort of vision when we perform surrounding vision tasks. Carrying out tasks such as conferences, paper, and electronic versions, it's linked to an increase in dry eye symptoms, therefore, among other factors, of altered blinking. (Rodríguez Montiel, 2015). This article intended to verify the phenomena of lying, deception, and selfdeception that are directly related to psychological problems and their treatments (Porcel Medina \& Gonzalez Fernandez, 2005). Among its defining features is the adoption of computational metaphor as a source of inspiration for the modeling of the structures and processes of the mind, and methodological functionalism, which legitimizes the study of mental processes and states (the "software") regardless of its physical installation base (the "hardware"). It is a computerized model of the human special abilities for reasoning and problem-solving skills. However, it is another modern language used in artificial intelligence (AI) and the logical extension that is based on first-order predicate calculus that includes an
\end{abstract}


inference engine that uses backward chaining. It is a non-procedural language, which indicates that the instructions do not have to necessarily be executed in the order that they have been entered. (Pino Diez \& Gómez Gómez, 2001) It is concluded that the specific causes of this ocular muscular activity constitute a true enigma located in the adjacent area of the midbrain. (García Alcolea, 2009).

The article will be based according to the title, authors, year of publication, abstract, citations, and bibliographic references since it is an experimental design project.

Keywords: Deception Detection, eye movements, neurocognition, artificial intelligence.

\section{INTRODUCTION}

Man is an animal that lies. Other animals also use appearances to survive, but the human being seems to be the only one capable of using lies about its person and its identity (Porcel-Medina and González-Fernández, 2005). In this context, behavioral and neurocognitive alterations related to lying may be a consequence of specific conditions, such as sleep disorders and respiratory complications (Esteller-Moré and Barceló-Mongil, 2009).

In contrast, means of evaluation based on questioning are of doubtful efficacy, and therefore objective assessment tools are required (Pino-Diez and Gómez-Gómez, 2001). It is appropriate to provide a historical synthesis of the scientific development in this field. Since the end of the 20th century, cognitive psychology has established direct relationships and it has also been consistently integrated into the field of the sciences of the mind known as cognitive neuroscience.

This encompasses the human processing systems which involve the mental and behavioral correlates of brain functioning, such as visual perception, attention, concentration, movement control, language; leading to particularly fruitful consequences in the study of memory, its functional architecture, and its clinical alterations, which were of great importance in its scientific study, providing an approach from various competencies.

This Multicompetent model comprises three types of structure: sensory, short-term, and long-term memories. It also involves two types of processing, bottom-up or data-driven, and top-down or conceptually driven. The cognitive neurosciences of the memory system of the mental structures are inspired by the analogy with the RAM and ROM memories of the computerized system.

Specifically, a memory system is a set of interrelated amnesic properties due to its neural substrate. In the case of short-term memory, which is considered as an active space of information transformation, it will depend on the duration and capacity in contrast to long-term memory. For the Multicompetent model, the memory system will be modified driven by the interest of two modalities called implicit or procedural and explicit or declarative (Burin, 2002). Hence, differential components must be established, which can be distinguished in Table 1 . 
Table 1: Types of memory and its differential characteristics

\begin{tabular}{c}
\hline Explicit or declarative memory \\
Intention to recall, deliberate \\
Conscious \\
Attentional effort \\
Recovery efforts
\end{tabular}

Flexible, modifiable

\section{Implicit or procedural memory}

No intention to recall

Unconscious

Automatic, unattended

Fires with associative keys

Relatively fixed patterns

Linguistic, propositional or image Multiple representational codes, including schemas and representation in working memory activation

Note: (Burin, 2002).

In regards to the subject of deception, it was initially considered that lying was a consequence of mental illness, however, further research through the eye and even facial movements indicates that these movements can be used as tools to detect if people are lying. Remarkably, many people seem to lie for their benefit, which, beyond being a pathological trait, could be an adaptive attempt. Therefore, selfdeception is also another component of relevance. For the lie hunter it is easier to detect disloyal behaviors in deception, hence, the objective of his research is not limited to clues, but to the search for knowing how lies, liars, and findings of lies differ from each other (Ekman, 2005).

The importance of psychology in this particular field can be related to a question that asks: How to determine that the mind can analyze itself without self-deception to discover the absurdity, the uselessness, and the danger of its way of functioning? Therefore, the mind can change in three ways: First: stop lying to itself (realism); Second: learn to lose (humility); and Third: learning to discriminate when to act and when not to act (wisdom). Thus, these three pillars are part of the psychological revolution (Riso, 2011).

Both, the historical and current components within this field have established the need for research that contemplates not only self-report and self-report measures but also current technological tools such as artificial intelligence software. In addition to considering biological measures composed of eye movements in the setting of the psychological measurement environment, it is also pertinent to address psychological symptomatology associated with Covid-19 in the current social turmoil.

\subsection{ARTIFICIAL INTELLIGENCE AND PSYCHOLOGY}

Artificial Intelligence (AI) is a branch of information technology, whose origin is centered on logic and cognitive sciences; and is capable of executing algorithms that have been developed for the creation of different automata with similar human-like capabilities. 
Nowadays, it is very common to associate AI with Psychology, because they have a common axis and an essential challenge which is to understand the processes that give rise to intelligent behavior and to develop solving problems techniques, adapting to the environment.

Currently, AI has developed research in the following fields:

- Educational psychology: Pedagogical innovation aimed to create new teaching styles.

- Cognitive psychology: To understand human capabilities and cybernetic prototypes.

- Organizational: Systems that facilitate the selection of different characteristics.

- Forensic: Emulate situations, e.g., crimes

- Clinical: Automata that can predict possible conditions.

- Neurosciences.

It is relevant to emphasize that humans are not closely related to Artificial Intelligence systems. The reason lies in the fact that machines do not think, feel, or have behavior; they are systems that process information and perform actions based on programming. The interconnection between these two disciplines has yielded results; some important technologies are listed below:

- Detection of psychological problems. Identification of mood.

- Detection of personality traits.

- Detection of aggressions and accidents.

- Detection of risky situations related to health.

- Assistance to people with mental pathologies.

- Intelligent tutors.

- Identification of psychological profiles, etc.

- Detection of behavior

\section{METHODOLOGY}

Descriptive analysis with a quasi-experimental design, which allows testing an initial hypothesis or explanation. Through controlled, explained, and documented experiences of the dynamics of the saccadic movement to approach the complexity of the mechanism that controls the eye movement through software that will measure microsaccades, which are movements of small amplitude, approximately 20 seconds of arc. To obtain particular conclusions from such measurement, which will then be tested quasiexperimentally taking into account the degree of the variables being studied to detect self-deception by the blinking process. 
This type of design requires a control group of subjects. The objective phenomena of the study are not directly observable, yet different constructs are analyzed. Evaluating the eye movement and its amplitude is essential to accurately capture the overall validity.

Therefore, the main goal of the study is to identify the psychological symptoms of Covid-19 determined by eye movements during deception.

Secondary objectives emerge from this general approach as follows:

- Analyze the backward and forward eye movements as part of the Covid-19 psychological assessment.

- Evaluate eye movements using the Assessment Criteria Indicative of Deception (ACID).

- Determine the degree of reliability of the ACID.

While this research uses very specific software to monitor the eye movements of people who present symptoms of Covid-19. It is precisely artificial intelligence, its main component, understood as a computer model of the reasoning capabilities and problem-solving skills of the human specialist. (Iberdrola, 2021).

Another important incursion of AI in Psychology is Eye Tracking (ET). It is said that ET is used to understand the connection between what people see and how that information is being processed. (Mur Baquer, 2021). Given the different techniques and tools applicable to ET, valued individual's information can be obtained such as:

- Where a person is continuously looking.

- Capturing individuals' attention.

- What the person's intentions are? The state of mind of this person.

Diagnose some type of disorder such as ADHD, dyslexia, eating behavior, neurodegenerative diseases such as Alzheimer's or Parkinson's, mental disorders such as schizophrenia, and spectrum disorders such as autism, depression, etc. (Arrabales Moreno, 2020).

Information technology experts, Stuart Russell and Peter Norvig have simplified the existing types of AI by placing them as follows:

- Systems that think like humans: Decision making, problem-solving, and learning. Example: Machine Learning.

- Systems that act like humans: Perform tasks in a similar way to people. Example: Robots.

- Systems that think rationally: They emulate the logical thinking of humans. 
- Systems that act rationally: They mimic human behavior.

Machine Learning (ML) is part of AI, which operates by creating self-learning systems after reviewing collected data to predict future behaviors, implying these systems improve autonomously without the need for human intervention. There are three different types of ML. Supervised learning has been considered one of the main tools that will be used for the creation of the detection system for saccadic movements.

Supervised learning also allows the system to be "trained" by providing labeled data. The need of labeling the new data is no longer needed once sufficient information is delivered. This system falls within the classification type.

Predicting a continuous value is another method used to predict new results by using combined parameters of new data. This system is categorized as the regression type. Science allows choosing between different types of algorithms:

- K nearest neighbors.

- Artificial neural networks.

- Support Vector Machine (SVM)

- Naive Bayes classifier.

- Decision trees.

- Logistic regression (ADP Editorial Office, 2019).

The hardware required performing different types of automatic learning, whether supervised, unsupervised or by reinforcement has a significant complexity. Therefore, to develop a well-trained system, the PC in which the algorithm is executed must have the following requirements:

- Operating System: Windows or Linux.

- Processor: Core i5.

- Memory: $9192 \mathrm{MB}$ of RAM.

- Graphics: GeForce GTX 970.

- DirectX: Version 11.

- Storage: $560 \mathrm{MB}$ of available space.

- The recommended requirements are discussed below:

- Operating System: Windows or Linux.

- Processor: Core i7.

- Memory: $12288 \mathrm{MB}$ of RAM.

- Graphics: GeForce GTX980Ti. 
- DirectX: Version 11.

- Storage: $560 \mathrm{MB}$ of available space (Vandal, 2020).

In addition, it was relevant to establish hypothetical questions to indicate: H1: Eye movements will detect deception through the identification system. E, H2: Eye movements will be directed by the neurocognitive process through the investigation system for deception.

\subsection{VARIABLES AND INSTRUMENTS}

The behavioral technique associated with implicit or procedural arguments is used. The variables and instruments provided, and the type of statistical variable analyzed in this study is shown below (Table 2).

Table 2 Summary of variables and instruments supplied.

\begin{tabular}{|c|c|c|}
\hline Variable & Instrument & Variable classification \\
\hline Eye Movements & & Adequate; Inadequate; Suitable: Not suitable \\
\hline Neurocognitive & & $\begin{array}{c}\text { Affirmation } \\
\text { Denial }\end{array}$ \\
\hline Detection of deception & & Logic \\
\hline Artificial Intelligence & & Cognitive \\
\hline
\end{tabular}

\subsection{PROCEDURE}

In deception, a process of refusing to rationalize logical arguments that are opposed to one's existence as well as to ignore important elements of relevance, which will be sampled from the Ecuadorian population with patients presenting with Covid-19 symptoms.

The procedure to be carried out will be as follows: (1) To contact authorities/managers of the University and the master's degree office; (2) To elaborate the survey, instruments, and informed consent by the Hal 9000 team; (3) To sign the informed consents; (4) To apply the survey and self-deception questionnaire; (5) Tabulation of data; (6) Test scoring according to established variables; (7) Writing of results.

\subsection{DATA ANALYSIS PLAN}

This review aims to achieve the recollection of relevant data within the field of experimental research on eye movements and the detection of deception. The subsequent analysis of the data obtained will allow concluding the following results:

- Analyze eye movements as indicators of deception within the information technology.

- Determine the degree of confidentiality of the deception-informed system

- Evaluate eye movements using the deception-informed system. 


\section{RESULTS}

\subsection{DESCRIPTIVE ANALYSIS}

The main contribution of this study is to establish deception through the saccadic movement using specific monitoring software which will measure the amplitude of the blinking to determine how individuals lie through questions that can be either true or false. The described methodology is strictly followed, and only relevant figures related to the objective will be presented. In addition, the different variables will be examined to determine the presence of corresponding association, using bivariate analysis.

\section{DISCUSSION}

Integrative psychology finds a fundamental basis in cognitive neuroscience with its rich knowledge of different systems, processes, and representations involved in the human mind.

The processing of an emotional event leads to the functioning of two modalities, where symptoms such as anxiety take an implicit pathway. These cognitive-behavioral approaches use various techniques to target conscious and unconscious representations, manifesting the work of the behavioral act, resulting in the change of beliefs and rules about oneself and the surrounding world (Burin, 2002).

To further understand the definition of lying or deception, we must analyze the authors who assert lying have different meanings, for instance, if the appearance of someone indicates a false impression, it means this individual is not lying but requires the approval of others to be accepted. Thereby, the liar can bring a good or bad will, understanding the person who lies is in the condition to discern between the true and the false and knows the difference.

Conversely, pathological liars recognize they are not telling the truth, but they cannot control their behavior. Other subjects tend to ignore they are lying and are often victims of self-deception. Furthermore, if an untruthful individual is involved, but does so believing in his lie, the fact of not experiencing it as false complicates the detection of this phenomenon.

There are two forms of lying: concealing and falsifying. The former involves when a person hides and retains certain information without disclosing the untruthfulness, the latter, occurs when the person who falsifies takes an additional step to not only retain the true information but also to present false information as valid or true... (Ekman, 2005). 


\section{REFERENCES}

Agrigoroaei, R., y Tapus, A. (2017). Detecting deception in a human-robot interaction scenario. HRI. http://dx.doi.org/10.1145/3029798.3038376.

Aragón, L. (2004). Psychometric foundations of psychological assessment. Iztacala Electronic Journal of Psychology, 7(4), 23-43.

Arrabales Moreno, R. (May 31, 2020). Artificial Intelligence and Psychology. Retrieved from Psicobótica: https://www.psicobotica.com/2020/05/31/inteligencia-artificial-y-psicologia/

Ayllon, T., Haughton, E., y Hughes, H. B. (1965). Interpretation of symptoms: Fac or Fiction? Behavior Research and Therapy, 3, 1-7.

Becerra, J. (2016). Psychometric assessment of psychic symptom simulation in the forensic setting. Rev. Esp. Med. Legal, 42(1).41-44. https://doi:10.1016/j.reml.2015.10.002

Burin, I. (2002). Cognition and Emotion: A neurocognitive view. UCES Journals. The subjectivity of Cognitive Processes, 33(19). http://dspace.uces.edu.ar:8180/xmlui/handle/123456789/529

Can, A., Kose, S., Solmaz, S., Kocaoglu, F., \& Hasan, Y. (2019). Reliability, validity, and factor structure of the Turkish version of the Structured Inventory of Malingered Symptomatology (Turkish SIMS). Psychiatry and Clinical Psychopharmacology, 29(2). https://doi.org/ 10.1080/24750573.2019.1599237.

Cartwright, A. (2018). May the choice be with you: assisting practitioners with selecting appropriate psychometric assessments for the medicolegal arena. Peer J.

Casado, M., \& Laguna, S. (2017). Somatic symptom disorder: from suspected simulation to cognitivebehavioral treatment. Clinica y Salud. https://doi: 10.1016/ j.clysa.2017.05.004.

ICD-10 (1992). Mental and behavioral disorders. Madrid: Meditor.

Cruz, C., Toloza, C., \& Larach, V. (2012). Modern hysteria: a synoptic view. Rev. Chil. Neuropsiquiatr, 50,(1):78.https://www.researchgate.net/publication/281443747_La_histeria_moderna_una_visionsinopti $\mathrm{ca}$

De Marchi, B., \& Balboni, G. (2018). Detection of feigned mental illness in forensic medicine: comparison of known groups and simulation design with MMPI-2, SIMS, and NIM. Peter J. https://doi.org/10.7717

Diaz, C. (2014). Simulation and dissimulation in evaluative medicine. Occupational Medicine and Safety, 60 (235), 379-391. http://scielo.isciii.es/scielo.php?script=sci_arttext\&pid=S0465-546X2014000200010

Echeburúa, E., Amor, P., Muñoz, J., Sarasua, B., \& Zubizarreta, I. (2017). Posttraumatic Stress Disorder Symptom Severity Scale according to the DSM-5: forensic version (EGS F). Yearbook of Legal Psychology. https://www.sciencedirect.com/science/article/pii/S113307401730020X.

Ekman, P. (2005). How to detect lies. Paidós. 
Ekman, P., \& Friesen, W. (2006). Hand movements. Journal of Communication, 22(4).338. https://doi.org/10.1111/j.1460-2466.1972.tb00161.x.

Espino, Orlando and Santamaría. (1998). Study of the effect of the figure on syllogistic reasoning through eye movements. Minerva institutional repository: Jornadas de Psicología del Pensamiento, 7. https://minerva.usc.es/xmlui/handle/10347/11936

Esteller-Moré, E., and Barceló-Mongil, M. (2009). Neurocognitive and behavioral alterations in childhood sleep-disordered breathing disorders. Acta Otorrinolaringologica española, 60. 325-331. https://doi.org/10.1016/j.otorri.2009.01.009

Etchepareborda, M.C. (1997). Journal of Neurology. 25. 709-714.

Gallach-Solano, E., Robledo-Algarra, R., Fenollosa-Vázquez, P., Izquierdo-Aguirre, R., and CanósVerdecho, M.. (2018). Pain and simulation: diagnostic and therapeutic challenge. Revista de la Sociedad Española del Dolor, 25(4), 237-241. https://dx.doi.org/10.20986/resed.2017.3522/2016.

Ganis, G. (2018). Detecting deception and concealed information with neuroimaging. Elsevier Inc. https://doi.org/10.1016/B978-0-12-812729-2.00007-0

Garcia, Alcolea and Englis. (2009) Why do rapid eye movements occur during sleep? Network of scientific journals of Latin America, the Caribbean, Spain, and Portugal. Median, 13, 1-7. https://www.redalyc.org/pdf/3684/368448454016.pdf

Glaser, S. (1982). Neuro-ophthalmology. Characteristics and techniques of eye movement recording. Salvat Editores.

181-194. http://www.omlab.org/personnel/lfd/Jrnl_Arts/Book_Chapters/018_Caract_tecnicas_registro_mov_ocul ar_1982.pdf

González, H., \& Santamaría, P. (2010). Predictive accuracy of the Structured Symptom Simulation Inventory-SIMS. Edupsykhé, 9(1), 3-22. https://dialnet.unirioja.es/servlet/articulo?codigo=3268852

Hall, H., Poirier, J. (2020). Detecting Malingering and deception. Forensic Distortion Analysis (FDA-5). Pacific Institute series on forensic psychology. Tercera edición

IBERDROLA. (2021). are we aware of the challenges and main applications of Artificial Intelligence? Retrieved 10202 2021, from https://www.iberdrola.com/innovacion/que-es-inteligencia-artificial

Impelen, A., Merchelbach, H., Jelicic, M., y Merten, T. (2014). The Structured Inventory of Malingered Symptomatology (SIMS): A Systematic Review and Meta-Analysis. The Clinical Neuropsychologist. https://doi:10.1080/13854046.2014.984763

Jiménez, B., \& Quintero, J. (2012). Ganser's syndrome: review of a case report. Actas Esp Psiquiatr, 40(3), 161-164. https://www.actaspsiquiatria.es/repositorio/14/77/ESP/14-77-ESP-161-164954818.pdf

Larrabee, G., Bianchini, K., Boone, K., y Rohling, M. (2017). The validity of the MMPI2/MMPI-2-RF Symptom Validity Scale (FBS/FBS-r) is established: reply to Nichols. TCN, 31(8), 1401-1405. http://dx.doi.org/10.1080/13854046.2017.1363293 
Masip, J. (2017). Deception detection: State of the art and prospects. Psicothema, 29(2), 149-159. http://dx.doi.org/10.7334

Mehrabian, A. (1981). Silent messages. Wadsworth Publishers. 1-152. http://www.kaaj.com/psych/smorder.html

Merckelbach, H., Peters, M., Jelicic, M., Ineke, M., y Smeets, T. (2006). Detecting malingering of Ganserlike symptoms with test a case study. Psiquiatría y neurociencias clínicas, 60, 636-638.

Mur Baquer, N. (2021). Eye-tracking: what is it, what types are there, and what is it for. Retrieved from Psychology and Mind: https://psicologiaymente.com/psicologia/eye-tracking

Nortje, A., y Tredoux, C. (2019). Good are we at detecting deception? A review of current techniques and theories. South African Journal of Psychology, http://dx.doi.org/101177/0081246318822953.

Paulson, K., Straus, E., Bull, M., MacArthur, S., DeLorme, J. y Dalenberg, C. (2019). Knowledge and Views of Psychological Tests among Psychiatrists and Psychologists. Forensic Psychology Research and practice, 19(2), 112-127. http://dx.doi.org/10.1080/24732850.2018.1546071.

Pino, R., and Gómez, A. (2001). Introduction to artificial intelligence: expert systems, networks. EDIUNO, 1-54. https://scholar.google.es/scholarcluster=9614714425218182504\&hl=es\&as_sdt=2005 scion $=0,5$

Porcel, Manuel, and González, R. (2005). Deception and lying in psychological disorders and their treatments. Papeles del psicólogo, 109-114. https://www.redalyc.org/pdf/778/77809206.pdf.

ADP Editor. (04 Apr 2019) What are the types of machine learning algorithms? Retrieved from ADP: https://www.apd.es/algoritmos-del-machine-learning/

Royal Spanish Academy. (n.d.). Cultura. In Diccionario de la lengua española. https://dle.rae.es/cultura?m=form

Rodríguez, M. (2015). Study of flicker characteristics and their relationship with saccadic movements, in different controlled reading conditions. [Master's thesis, Polytechnic University of Catalonia]. (2015). 152.

Romero, S. (2017). Psychophysiological detection of polygraph to neuroimaging deception. Udima Blogs. https://blogs.udima.es/psicología/detección-psicofisiológica-del-engaño

Rosenfeld, J. (2019). P300 in the detection of hidden information and deception. Scientific journal of psychophysiology research, 57. (7). 1-12. https://doi.org/10.1111/psyp.13362

Ruiz Pérez, J., Quevedo, O., \& Sirven, C. (2018). Self-deception and impression management in Colombian inmates and students. Granada, Spain.

VANDAL. (May 18, 2020). Machine Learning: Episode I. Retrieved from VANDAL: https://vandal.elespanol.com/requisitos/pc/machine-learning-episode-i/41995\#p-13 